Tesis. Año 12, 11(13), 2018, 43-58

\title{
La prisión: mecanismos de poder, suplicio y ex- clusión. El fracaso del sistema penitenciario en Los hijos del orden de Luis Urteaga Cabrera
}

\author{
César Humberto Olivares Acate \\ cesarolivaresacate@gmail.com
}

\section{Resumen}

En este artículo se aborda la manera en que la prisión es representada, dentro de la diégesis de la novela Los bijos del orden, como un instrumento de suplicio y exclusión del sujeto subalterno. En este sentido, la cárcel viene a constituir un claro medio de segregación de las clases oprimidas, cuya represión se encuentra cargada de trasfondos discriminatorios y racistas. Además, en esta misma diégesis se explica el modo en que las modernas reformas del sistema penitenciario fracasan cuando intentan corregir las conductas delictivas de los protagonistas principales de la novela estudiada.

Palabras clave: Luis Urteaga Cabrera, Los hijos del orden, subalternidad, prisión.

\begin{abstract}
This article present the way as the prison is represented inside narrative's development of the facts in the novel Los hijos del orden, like an instrument of torture and exclusión of the subaltern subject. In this sense, the jail become to represent a clear way of segregation of the oppressed clases which repression is overloaded with discriminatories and racist backgrounds. In addition to the plot, it explains the way in which the modern reforms of the penitentiary system fail down when they try to correct the criminal conducts of the protagonists of the novel studied.
\end{abstract}

Key words: Luis Urteaga Cabrera; Los hijos del orden; subalternity; prison. 


\section{La prisión: mecanismos de poder, suplicio y exclusión. El fracaso del sistema penitenciario en Los hijos del orden de Luis Urteaga Cabrera}

\section{Introducción}

La novela Los hijos del orden, del escritor cajamarquino Luis Urteaga Cabrera, narra la historia de un grupo de niños y adolescentes transgresores de la ley sobre quienes ha caído una sentencia de reclusión en el instituto de rehabilitación de menores delincuentes de Lima. En este lugar conviven, emiten sus discursos y reciben un trato basado en la violencia, crueldad y corrupción por parte de las autoridades penitenciarias. La mayoría de estos menores de edad han delinquido motivados por el hambre, la miseria y el abandono que les ha tocado vivir en la capital. Muchos de ellos son migrantes que han llegado a Lima desde distintos lugares del ande (zonas acosadas también por la indigencia), atraídos por la promesa de desarrollo que despiertan las ciudades y su proceso de modernización. Sin embargo, apenas llegados a la urbe, esta se convierte en el monstruo limitador de oportunidades que empuja a estos seres migrantes del centro conservador y prejuicioso hacia a las partes periféricas e inhóspitas de la capital.

\section{Primeros conflictos: violencia simbólica e interrelaciones de poder}

El primer acontecimiento narrado en la novela ubica a los personajes principales de la historia - adolescentes migrantes o hijos de migrantes que abandonaron sus pueblos y llegaron a Lima en busca de la promesa de la modernidad que ofrecían las ciudades - en el único órgano de represión juvenil del Estado: la prisión-reformatorio. Las primeras páginas dan cuenta de la visita de los familiares al Centro Juvenil de Diagnóstico y Rehabilitación de Lima, más conocido como "Maranguita". Los internos tienen derecho a una visita semanal y esta no puede darse a solas. Los mecanismos de control obligan a revisar a las madres y demás familiares antes de permitirle la entrevista con los jóvenes reclusos. Aquí se da el primer caso de verticalidad y prepotencia en las interrelaciones de los personajes, pues la inspección no ocurre necesariamente en términos amables. 
Ante la inquietud de las madres que esperan su turno de ingreso, la voz de un representante del orden, enérgica y despectiva, sobresale entre las demás: “-;Guarden silencio, carajo! ¡Dónde se creen que están, en sus chiqueros?” (p. 13). ${ }^{1}$ Este acto de prepotencia canalizada en el grito nace de considerar al otro como un ser inferior, carente de buenas costumbres, intelectualmente deficiente y predispuesto al vicio y a la inmoralidad, al que se juzga por su vestimenta, nivel de uso de la lengua y modales. Entonces se presenta el primer conflicto entre un representante del Estado represor y un sujeto triplemente subalternizado $^{2}$ dentro de la historia. Se evidencia tensión y desprecio por parte de la autoridad, ya que en su actuar operan los mecanismos de exclusión que, a nivel de nación, se han pensado para los sectores subalternos. Entonces la madre del interno muestra humildad, sumisión, temor, pues pertenece a una clase social baja; si no es sumisa ante la humillación de la autoridad, la visita tan esperada a su hijo podría no concretarse.

La mujer que se encuentra en la cabecera de la cola da un paso, da otro, la expresión de su rostro se transforma, ipor fin!, se suaviza. Da un paso y su cuerpo oculta el angosto espacio que permite el brazo del vigilante, buenas tardes jefe, se agacha, se introduce, su gesto de alivio, una canasta en sus manos y desaparece de la vista de la muchedumbre. (p. 13).

En una escena posterior, cuando la madre pregunta por su hijo y brinda los nombres y apellidos completos del mismo, esta nominación propia, si es que alguna vez el interno la tuvo, ahora no existe más. La celda despersonaliza, resemantiza las acciones y los nombres, quita identidad, configura una nueva personalidad. Los internos pierden hasta el derecho de usar su verdadero nombre: los llaman, los renombran. Mediante este acto de violencia simbólica, ${ }^{3}$ el sistema represor les anula la conciencia individual de sujeto, les despoja de una existencia anterior; busca hacerle entender al reo que su vida empieza en la cárcel y termina allí. Que no hay escapatoria, menos aún opción para reformar su conducta.

-iiEse Francisco Urbiola... visita!!

$\mathrm{Su}$ ronca voz retumba en el edificio dominando todos los ruidos. La memoria de Huamán acude en su ayuda, ah, murmura, el cabrito Cococha [...], por un lado, por otro, voces adolescentes repiten el llamado: ¡Cococha?... ;Cococha! (p. 15) [cursivas nuestras].

Sin embargo, el enfrentamiento más importante que ocurre en las primeras páginas de la novela, y que se tornará constante dentro de la interrelación recluso-autoridad, sucede entre Carasa, un joven interno avezado en el uso de arma blanca y Tello, ${ }^{4}$ un representante del orden institucional experto en maltratar a los internos y en promover el consumo de drogas y la ingesta de bebidas alcohólicas entre ellos. Resulta interesante señalar que este enfrentamiento entre 
subalterno y agente represor no es el primer intento por abordar la horizontalidad de las relaciones, sino la opción para negar y revertir la autoridad del vigilante de la ley mediante sus propios argumentos represivos: la violencia. Este enfrentamiento con arma blanca por parte del interno (Carasa) nace de un arranque de solidaridad ante el compañero caído (Piojera), quien momentos antes de la pelea era severamente castigado por el custodio del orden (Tello). Estamos ante una respuesta violenta que nace de la indignación ante la injusticia y el abuso de autoridad; 5 este hecho le otorga a Carasa una sensibilidad y humanidad sui géneris, pues a diferencia de las indolentes políticas represivas del Estado que muestran al delincuente como un ser desalmado, cruel y merecedores de castigo, este hecho de luchar por el compañero maltratado, más que un código de honor del hampa, lo presenta como un sujeto provisto de algunos valores, a quien la miseria, el abandono, el hambre y los malos tratos en prisión no han podido sustraerle el sentido de la solidaridad.

Recostado en la baranda de la escalera inmediata a la reja, Carasa se alarma al escuchar los alaridos, se desconcierta: ¿dónde... quién?... En un instante se han formado ante él movedizas murallas que se desplazan desordenada, vertiginosamente de un sitio a otro en pos de aquella voz gruesa, colérica, inubicable: ¡Párate, mierda! Y esos aullidos dolorosos, agudos, que acompañan la voz. Carasa estrella su cuerpo contra una muralla, forcejea desesperadamente, logra romperla, avanza, desorientado, a través de ella. De pronto un claro pleno de luz, esa espalda voluminosa, ese brazo en el aire blandiendo la vara de goma, y esa pierna alzándose, cayendo, alzándose y cayendo con furia sobre aquel cuerpo menudo que patalea, grita, se revuelca en el piso, vocifera. ¿Tello?, la pierna ágil, incansable, la voz ¿̇te vas a parar, mierda!, su voz. Carasa está detenido, perplejo, sus ojos dilatados, las manos crispadas ¡su compadre Piojera!, su rostro contraído, degradadas sus facciones, jla putesumadre!, y arroja su cuerpo contra la manga enardecida, envolvente y la desbarata... (pp. 15-16).

El enfrentamiento lo gana el interno. A pesar de su corta edad, Carasa demuestra pericia en el uso de arma blanca; por otro lado, el agente del orden, ducho en emplearla para reprimir y castigar a los internos por cualquier motivo, evidencia su torpeza en el manejo de la vara. El agente Tello, "demudado, tasajeada la ropa, el semblante desfigurado por una mueca de terror" (p. 18), tiene que ser socorrido por sus colegas, quienes inmediatamente derriban a golpes de fusil al "saboteador" del orden, para que los demás no imiten el "mal ejemplo". Es decir, aparte de tenerlos encerrados en prisión, resulta necesario castigar al cuerpo para poder regenerar y modificar las conductas remisas y delictivas de los subalternos. 


\section{La prisión no elimina el suplicio del cuerpo}

Para abordar el tema de la prisión y los efectos que causan en el cuerpo y alma de los reclusos, resulta importante consultar el estudio realizado por Michael Foucault en Vigilar y castigar (1992). Un dato importante que brinda Foucault es que la creación de la prisión, como lugar donde se purgan penas, ha dado paso a la desaparición de los suplicios:

Ha desaparecido el cuerpo supliciado, descuartizado, amputado, marcado simbólicamente en el rostro o en el hombro, expuesto vivo o muerto, ofrecido en espectáculo. Ha desaparecido el cuerpo como blanco mayor de la represión penal. (1992, p. 16).

Esta reforma penitenciaria es vista como un logro de la civilización, un paso importante en la formación de ciudades modernas. Ya no se muestra el sufrimiento y la mutilación del cuerpo como un espectáculo circense, sino que se encierra el cuerpo delictivo, se lo aísla; de esta manera se debilita su estado de ánimo, se mata de a pocos su alma. Sin embargo, hay que considerar que este ideal postulado por penólogos europeos ha fracasado en su aplicación en el régimen carcelario peruano y latinoamericano, ya que en su denodado esfuerzo por alcanzar la modernidad en su sistema penitenciario, se han terminado solapando torturas y siendo cómplice de espantosas muestras de barbarie en las diferentes prisiones existentes en su territorio ${ }^{6}$. En este sentido, resulta interesante acceder al debate a partir de lo investigado por Carlos Aguirre, pues parece que los sistemas penitenciarios de América Latina todavía conservan sus prácticas coloniales. En este sentido, se debe tener en cuenta que el encarcelamiento de delincuentes se debe a "una práctica social regulada más por la costumbre que por la ley y designada simplemente a almacenar detenidos, sin que se haya implementado un régimen punitivo institucional que buscara la reforma de los delincuentes" (Aguirre, 2011, p. 192).

Lamentablemente, lo descrito en el párrafo anterior sigue vigente en el sistema penitenciario peruano, pues sus cárceles están lejos de reformar las conductas delictivas de los prisioneros; por el contrario, contribuyen a acentuarlas, debido a que no les interesa la promesa de "reformar a los criminales a través de mecanismos humanitarios, sino la posibilidad, mucho más tangible y realizable, de reforzar los mecanismos de control y encarcelamiento ya existentes" (Aguirre, 2011, p. 198). En otras palabras, el suplicio en las cárceles está lejos de ser un hecho fortuito, ya que parte de la visión de las propias autoridades y grupos dominantes, quienes confían más en crueles castigos para los reclusos que en el encarcelamiento del cuerpo para purgar el delito.

Toda esta realidad es descrita con mirada crítica en la novela Los hijos del orden de Luis Urteaga Cabrera, la misma que denuncia el fracaso del sistema pe- 
nitenciario de las ciudades en proceso de modernización, como la Lima de los años 60, pues el hecho de purgar condena encerrados en una prisión-reformatorio como "Maranguita" no libera a los reclusos de los suplicios y castigos físicos de los verdugos, hasta podría decirse que gracias al encierro resulta más fácil castigar al cuerpo, ya que el prisionero no tiene escapatoria posible. No obstante, es importante aclarar que estos castigos, que aún suceden en las prisiones, están dirigidos a grupos subalternos "incivilizados", "bárbaros" y pobres; mas no a ciudadanos cultos, adinerados y con "influencias", quienes escasamente pueblan las cárceles del Perú.

No solo se trata de que las penitenciarías fracasaran en el cumplimiento de sus promesas de tratamiento humano, sino que, de hecho, fueron utilizadas para sostener un orden social en el que la exclusión política y social de amplios sectores de la población se convirtió en uno de sus baluartes. (Aguirre, 2011, p. 197).

En otras palabras, antes que buscar la reformación del interno y posibilitar su reinserción productiva en la sociedad, las penitenciarías en los países premodernos se han instituido para controlar y castigar severamente a los que incurren en delito. De esta manera, se evidencia la ineficiencia de las políticas carcelarias, pues con la creación de la penitenciaría ${ }^{8}$ - o de la ampliación de esta-, en vez de disminuir los tratos inhumanos, el uso de la violencia, el racismo y el autoritarismo han aumentado de un modo atroz.

Es cierto, el castigo desaparece para el que delinque, pero solo como espectáculo, en su dimensión teatral y aleccionadora. Entonces tiene que darse a escondidas, para no afectar la imagen de la justicia que ya ha dictado su veredicto con la prisión efectiva. Esta conclusión de Foucault se evidencia en Los hijos del orden, pues los castigos a los internos ocurren puertas adentro, de manera solapada (no olvidemos que los internos de la novela son menores de edad); son castigos ejemplificadores y únicamente mostrados como espectáculo a los demás internos de lo que les puede pasar si se muestran renuentes a las órdenes o si retan a la autoridad en cualquiera de sus niveles. La punición tenderá, pues, a convertirse en la parte más oscura del proceso penal. Hacia afuera todo es silencio, pues está en juego "el prestigio" y la seriedad de la institución. Esto lo evidencian las palabras que Felipe Urquizo, Director del Instituto de Rehabilitación de Menores, les dirige a sus propios subalternos, ya que busca por todos los medios posibles que no se sepa el destino del interno Carasa, a quien ellos han desaparecido, torturado, asesinado y enterrado de manera clandestina en el mismo huerto del centro de rehabilitación de menores: "Fue mi deseo, e hice recomendaciones en tal sentido, que el suceso no trascendiera. Me propuse mantenerlo en secreto, exclusivamente como un problema interno" (p. 35). 
Luego, cuando inspecciona el lugar en el que había sido enterrado el cuerpo de Carasa, muestra su satisfacción por lo oculto que debía de quedar el hecho, ya que este interno victimado en sus instalaciones, ha sido reportado a las autoridades como uno de los cabecillas que logró fugar de la prisión-reformatorio: "No se nota absolutamente nada - dice- Yo que he realizado mil inspecciones oculares, puedo asegurarle que no hay un solo indicio de haberse removido esta tierra. ¡Lo felicito!, un buen trabajo, sí” (p. 125).

Además, si hechos como estos llegasen a la esfera pública, ocasionarían reclamos y protestas por parte de los familiares de las víctimas. Por otro lado, resulta interesante anotar que lo que más preocupa a las autoridades, respecto del castigo físico de los reclusos, es el peligro de que este pueda darse por venganza o motivado por escaramuzas personales, ya que es de vital importancia que el reo no se entere de que los suplicios ocurren como parte de una serie de políticas represoras de la institución. Por eso, el Jefe de Conducta llama la atención a Tello, pues la golpiza que le propinó a Piojera fue motivada por "calenturas" personales:

-iPero debiste llevarlo a mi despacho, pues! -dijo el Jefe de conducta¿Por qué no lo hiciste?

-Lo estaba llevando -dijo Tello-, pero no se callaba. Ni quería caminar, tampoco. Por cada empujón que le daba, una mentada de madre.

- ¡Y por una huevada así perdiste los papeles? - dijo el Jefe de Conducta.

- ¿Y quién no? -dijo Tello-. A ver a usted que le saque la madre un mierda de estos... ¿Se va a quedar tranquilo?

-Claro que no; pero no por eso voy a catanearlo delante de todo el mundo. Sería una estupidez. Y eso es lo que tú has hecho, con los resultados que has visto. (p. 26).

Esto pone en evidencia que los castigos físicos a los reclusos cumplen su real función si es que se dan como políticas represivas a nivel institucional, entonces no hay escapatoria para el prisionero, pues el suplicio ocurre como recurso penitenciario del Estado, con plena aprobación y conocimiento de sus autoridades.

Para Foucault, es la propia condena lo que se supone marca al delincuente, y esto es suficiente castigo para su delito, pues se deja de castigar al cuerpo para castigar el espíritu. En Los hijos del orden, los internos de Maranguita ya han sido sentenciados (según las normas anotadas dentro de la historia, los internos deben pasar de dos a tres años en la prisión-reformatorio), pero los suplicios no han desaparecido. Aquí surge una hipótesis interesante: a pesar de estar encerrados, los castigos corporales no disminuyen debido a que los internos (cabecillas) están en un enfrentamiento constante con los agentes del orden. Por su parte, estos celadores del orden manifiestan que el encierro del cuerpo no es suficiente castigo para el delito, y que la única forma de corregir a los internos es 
a través del golpe y la tortura; solo aplicando estos métodos punitivos de corrección es posible reinsertar a los reclusos a la sociedad y hacerlos sujetos de bien. Estos argumentos guían la reflexión del jefe de conducta, cuando descubre un plan de fuga por parte de los internos:

Las celdas no eran castigo, le creyera el señor Director y que le disculpara la palabrota pero esos se cagaban de risa cuando se los metía a las celdas. ¡No era ningún castigo para ellos!, era, más bien, una ocasión de haraganería y era contraproducente castigarlos de esa manera. ¡Había que pensar en otra cosa!, algo que les escarmentara de verdad, los disuadiera de andar metiendo desorden, les sirviera como ejemplo y a la vez como demostración para la dirección de Penales donde andaban medio saltones. (p. 125).

Una de las tramas principales de la novela tiene que ver con el motín e intento de fuga de los internos, escape que fue detenido y escarmentado con todo el rigor por las autoridades penitenciarias, quienes llegaron a saber del mismo gracias a la delación de Zorro, un interno enterado de los detalles del plan y enemigo a muerte de la pandilla organizadora de la fuga. Ocurre que el grupo liderado por Guto (Augusto Minaya Grández) se informó de que las autoridades penitenciarias de "Maranguita" pensaban construir un pabellón de máxima seguridad con apoyo de capitales extranjeros y propuso a los integrantes de su banda - algunos de ellos poseían conocimiento de albañilería - para participar en su edificación. La idea era que mientras colocaban los cimientos de la nueva construcción, debilitarían la estructura de la reja principal de la prisión; de tal manera que, en una fecha y hora previstas (se había pensado el día de la inauguración para asestar el golpe), la fuga sea posible. No obstante, este prometedor plan, muchos de los internos dudaron en unírseles y otros fueron comprados por las autoridades penitenciarias para delatar lo organizado. Como es de imaginar, la huida fue desbaratada y los revoltosos severamente castigados. Hasta aquí las aguas parecieron retornar a su cauce habitual, de no ser por el hecho que, gracias a los perros de la correccional, los internos descubrieron el cadáver de Carasa a medio desenterrar. Con el cuerpo putrefacto cargado sobre los hombros, los cabecillas marcharon en procesión con el cadáver a cuestas para encender los ánimos de los demás internos. La rabia y la indignación se apoderaron de ellos a tal punto de anular su miedo y desencadenar un verdadero motín en el cual destrozaron e incendiaron las principales instalaciones del reformatorio. Demás está decir que la protesta fue sangrientamente reprimida. Los que alcanzaron a fugar fueron recapturados y marcados como cabecillas de la protesta.

Las páginas de la novela que narran este hecho describen la crueldad con la que castigan el cuerpo de los evasores frustrados, represalia importante y ejemplificadora por parte del sistema autoritario, que, a través de estos actos de 
barbarie, muestra lo que les espera a los que se atreven a retar al Estado y a sus instituciones. El discurso plantea esta fórmula: "imponer castigos ejemplares a esos cabecillas y verán cómo se moderan” (p. 319). Para este escarmiento se ha convocado a personal militar, experto en suplicios físicos. El propio director del Instituto de Rehabilitación de Menores justifica la violencia empleada al describir a estos jóvenes delincuentes como "incorregibles" y justificar así el ingreso de personal militar antimotines a las instalaciones de "Maranguita":

¿Acaso todo esto no es manifestación harto elocuente de su salvajismo? ¿Cómo querían que los redujéramos, con ruegos, con caramelos? [...] Naturalmente, nos vimos obligados a solicitar la presencia de la guardia de asalto. Hay que comprender que estos muchachos no son adolescentes normales. No lo son, de ninguna manera; son delincuentes de lo más sanguinarios... (p. 316).

Sin embargo, el suplicio final y que a la postre llevaría a la muerte de tres jóvenes internos identificados como cabecillas del motín (Guto, Chamo y Pigua), se da en las instalaciones de la prisión denominada El Frontón, ubicada en una isla, frente al Callao. Hasta allí habían trasladado a los internos, por la madrugada, con documentos fraguados en los que se había cambiado sus fechas de nacimiento. Ahora, como "mayores de edad", los tres internos iban a recibir la tortura final entre barrotes y el estruendo fúnebre de las olas del mar. Para beneplácito de las autoridades, ninguno de los tres reclusos más peligrosos del sofocado motín "tenía parientes, familiares cercanos o allegados que pudieran presentar reclamaciones y causar problemas posteriores" (p. 332). Es decir, se cumplía con todas las condiciones para castigar el cuerpo sin correr el riesgo de un futuro escándalo. Por tal motivo, esta última tortura narrada en la novela pone sobre el tapete la impotencia e ineficacia de las autoridades para corregir las conductas de los reclusos, a los que se priva de toda esperanza de sanción civilizada. Las tres últimas páginas de Los hijos del orden (pp. 337-340) narran la brutalidad escalofriante de la tortura. A continuación, se transcriben algunos fragmentos que fundamentan lo expuesto:

Nada dirán los certificados sobre los primeros golpes. Sobre las primeras punzadas pavorosas. Sobre los primeros alaridos espeluznantes arrancados a sus gargantas. Las violentas convulsiones. Los saltos de sus cuerpos sobre el piso. Los gritos. Los desesperados gritos con que ustedes piden que los maten, que los acaben de una vez [...] (p. 338).

No dirán los certificados que después, en la oscuridad reinante, serán ustedes arrastrados hasta el borde del acantilado, que amarraron sogas a los grilletes de sus muñecas, que son descolgados por las grietas de las peñas golpeadas por la marejada, y el agua salobre, helada, caliginosa de las olas les lame primero los pies, los tobillos, lava la sangre, desprende los coágulos de sus piernas, cubre las contusiones de sus rodillas, diluye 
los grumos sanguinolentos de sus sexos, bate sus vientres retirándose con fragmentos de piel azulosa, amoratada, vellosidad y cuajarones de sangre ennegrecida [...] (pp. 339- 340).

Los certificados expedidos por el Médico forense serán escuetos, dirán lo mismo para Augusto Minaya Grández alias 'Guto', para Hugo Carranza Estrada alias 'Chamo', para Roque Cajavilca Tanta alias 'Pigua': edema pulmonar agudo. No dirán, no habrán de revelar jamás que atónitos, contrariados o decepcionados, los hombres de la Isla no encontraron en ustedes la resistencia que esperaban. [Énfasis mío] (p. 340).

Resulta reveladora esta última cita, pues el discurso oficial solo les devuelve sus nombres propios a los personajes después de que estos han muerto, como acto simbólico de respeto o reconocimiento póstumo, pues se testifica que tuvieron, como todos, una identidad. Por otro lado, la expresión resaltada en cursivas de la última cita constata a todas luces que no se trataba de feroces delincuentes que nacieron para el crimen, sino de niños y adolescentes a quienes Lima y su cruel realidad les negaron la promesa de la modernidad, la misma que lograron acariciar, después de tantos sufrimientos, otros migrantes que sí triunfaron en esta tierra falsamente prometida.

Acerca de los mecanismos de suplicio y tortura institucionalizados como vía desesperada para reformar la conducta de jóvenes delincuentes, es interesante recurrir a las siguientes reflexiones de Carlos Aguirre (2011):

Cuando el Estado se hace cómplice de estas prácticas -por acción o por omisión- en lugar de combatirlas, los supuestos hechos "aislados", los "excesos" o los actos aparentemente "individuales" terminan siendo parte de una estructura (en el sentido de algo duradero, formativo de las prácticas sociales y fundamento de la forma en que se organiza una sociedad) que los conecta con prácticas más sistemáticas de abuso y exterminio: las fosas comunes o las masacres de presos son la exacerbación del mismo impulso vengativo que demanda la eliminación física del delincuente $[\ldots]$ (p. 21)

Estas prácticas sistemáticas de abuso y exterminio también se esconden detrás de los insultos y el desprecio a los que son sometidos diariamente miles de trabajadores de la clase baja por las altas élites gobernantes. Entonces, sesgadamente de lo que ofrecen otras miradas, los mecanismos de punición en los centros penitenciarios se han basado en grandes dosis de exclusión racial, socioeconómica y en la necesidad de controlar el accionar de las grupos subalternos (en este caso, el de los niños y adolescentes desprotegidos por sus padres, abandonados por las autoridades y reprimidos por el Estado), que puedan alterar el orden, la paz y el silencio que necesitan los "sistemas progresistas" para demostrar los éxitos políticos de sus gobiernos. 


\section{La prisión para menores de edad: el fracaso de los centros reformatorios o correccionales}

La creación de reformatorios o centros correccionales obedecen a la necesidad de buscar una prisión especializada en castigar delitos perpetrados por menores de edad. ${ }^{9}$ Para explicar y sustentar el problema del crimen y el delito cometido por estos menores, y de los objetivos, características y procedimientos de estos centros de represión para infantes y adolescentes, tenemos que ubicar, necesariamente, el mundo representado ${ }^{10}$ de la novela en un espacio histórico concreto. Las tramas y desenlaces principales de la novela suceden en el "Instituto de Reeducación de Menores Delincuentes" (p. 265), nombre oficial del centro reformatorio en la ficción, aunque el flash informativo de Panamericana Televisión (también en la ficción), comunica que se trata del "Instituto de Rehabilitación de Maranga" (p. 261) y, con el sensacionalismo característico de las crónicas policiales, detalla que

los distritos de San Miguel, en Lima, y Bellavista, en el Callao, han sido declarados en estado de emergencia [...], en salvaguarda de la seguridad social, a raíz de la espectacular evasión que han consumado algo más de una veintena de menores delincuentes (p. 261).

Lo que interesa de la cita anterior es que hace referencia a un centro correccional de menores, cuya existencia podemos constatar en la realidad: el actualmente denominado Centro Juvenil de Diagnóstico y Rehabilitación de Lima, conocido también como "Maranguita". Este centro correccional, fundado en 1945, no fue el primero de Lima. Históricamente, existieron dos que anteriormente intentaron satisfacer la demanda de castigo para menores delincuentes. La primera fue la Escuela Correccional de Menores, inaugurada en 1902, en una casona del centro de Lima, ubicada entre las calles Chota y Progreso. Tenía como objetivo principal "reformar, a través de la educación y el trabajo, a los menores entre ocho y dieciocho años que observaban conductas consideradas inmorales" (Aguirre, 2011, p. 165). Se estableció, para que la reformación de los internos sea efectiva, un encierro no menor de dos años y no mayor de tres, lapso en el cual los menores serían obligados a estudiar cuatro horas diarias y otras cuatro las dedicarían a trabajar en talleres de carpintería, zapatería, mecánica, hojalatería y sastrería. Esta escuela correccional fracasó, pues lejos de reformar a los internos, los maltratos, el hacinamiento y la corrupción contribuyeron a que se convirtieran en "una escuela de formación de futuros delincuentes y en un escenario explosivo de violencia y desorden" (2011, p. 169). Luego de ocho años de funcionamiento, este centro correccional fue cerrado.

La segunda escuela correccional de Lima se inauguró en 1918, con el nombre Granja-Escuela de Surco, renombrada luego como Reformatorio de Menores de Surco, institución que también fracasó por la violencia y el trato inhuma- 
no brindado a los internos. A estos vejámenes se añadió la explotación laboral a la que se vieron sometidos los niños y adolescentes de esta institución, pues con la justificación de que se precisaba enseñarles oficios útiles y máximo aprovechamiento del tiempo, "la Granja-Escuela empezó a ceder menores en alquiler a hacendados necesitados de mano de obra barata en las chacras y haciendas de los alrededores" (2011, p. 171).

La tercera escuela correccional de Lima, la que presenta como escenario principal el mundo representado de la novela, nació bajo el nombre Escuela Correccional de Varones de Maranga y fue fundado el 12 de julio de 1945, durante el Primer Gobierno del Presidente Manuel Prado Ugarteche. ${ }^{11}$ Después de algunos años de funcionamiento cambió su denominación y adoptó el nombre actual de Centro Juvenil de Diagnóstico y Rehabilitación de Lima. $\mathrm{Su}$ modelo rehabilitador de menores se fundaba en tres pilares: esquema correccional-moralista, escolaridad básica y formación laboral a través de talleres ocupacionales. Uno de sus objetivos principales consistió en brindarle al interno una rehabilitación integral y promover su reinserción a la sociedad. Sería interesante, si entramos al texto de ficción, hacer un contrapunto acerca de los fines del Instituto de Reeducación de Menores Delincuentes, expuesto por su director, Felipe Urquizo:

Felizmente ya hoy existen funcionarios que tienen un cabal concepto y conocimiento de las modernas técnicas para tratar a los jóvenes descarriados, con problemas de conducta, pudiendo felicitarme de contar con un calificado plantel de subalternos [...] en la tan delicada y por qué no decirlo, laudable misión en que nos hallamos empeñados, cual es la de reeducar y enseñar a trabajar a los miles de muchachos que pasan por este Instituto en demanda de afecto y protección sincera. Empero, el ideal de convertirlos en hombres de bien, que nos hemos señalado como una meta, como la culminación de nuestras más patrióticas aspiraciones, requiere, exige, para un exitoso cumplimiento, comodidad en las instalaciones, calidad en la comida y un ritmo creciente en las mejoras que con tan buen auspicio hoy se inician. (p. 218) [Énfasis mío].

Por supuesto que estas intenciones filantrópicas, enunciadas por el Dr. Urquizo en su discurso, estaban destinadas a causar un grato asombro a los visitantes al centro de rehabilitación, quienes asistieron a la inauguración del nuevo pabellón construido por los mismos reclusos. La reacción de los internos, que también estaban presentes en la ceremonia, ante estos anuncios, fue la de un rechazo total que solamente produjo lisuras dichas a media voz, ya que alrededor de ellos había muchos inspectores custodiando el orden. Por lo tanto, podemos concluir que las políticas benéficas pensadas para los reformatorios han fracasado, ya que sus pilares no han sido debidamente aplicados y, por el contrario, han dado paso a un trato basado en la crueldad, violencia y corrupción. 
Hasta aquí, el reformatorio o centro correccional de menores no se diferencia de una prisión cualquiera pensada para albergar a los más avezados delincuentes, pues el uso extendido y constante de la violencia como medida correctiva ${ }^{12}$ lo aleja de los ideales reformatorios y de la pensada reinserción a la sociedad de estos niños y adolescentes que han atentado contra la ley ${ }^{13} \mathrm{y}$ el orden establecido. Lo verdaderamente preocupante, y esto es lo que denuncia Los $b i-$ jos del orden, reside en que estos castigos se apliquen con doblegada crueldad a niños y adolescentes, cuyas posibilidades de defensa son menores debido a su escasa edad y a su frágil contextura física. Los escasos momentos de orden que reina en la correccional, según se narra en la novela, se logra gracias al terror y a los castigos corporales infligidos a estos internos que, en teoría, deberían estar protegidos por las políticas del Estado.

Tal vez una explicación para la dureza del castigo que recae sobre los internos de los centros reformatorios tenga que ver con el lugar subordinado que ocupan los niños en las familias, las escuelas y la sociedad, y con la cultura fuertemente autoritaria impuesta desde tiempos de la colonia, que ejerce control y disciplina sobre la crianza de los hijos. Según lo manifestado, los niños debían obedecer en todo, no participar en las conversaciones de los adultos y cumplir de manera íntegra con sus obligaciones escolares (donde también se los castigaba corporalmente bajo el lema "la letra con sangre entra" y contaba, por supuesto, con la complicidad de los padres). En consecuencia, si algún niño demostraba díscolo comportamiento o perpetraba algún delito, qué duda cabe, se debía al escaso rigor con que los padres lo habían criado en casa. Carlos Aguirre (2001) ensaya una reflexión fundamental al respecto:

Las ideas dominantes, puestas en práctica en hogares y escuelas, sobre cómo tratar a los niños e imponerles la obediencia; las nociones comúnmente aceptadas sobre cómo castigar a los delincuentes; la imposición de formas de control militarizadas, con su combinación de despotismo y corrupción; la flagrante negligencia estatal en el ejercicio de sus deberes de contraloría de estas instituciones; y los intereses privados que buscaban explotar el trabajo de los menores, fueron todos factores que se combinaron para dar forma a instituciones correccionales que, en lugar de reformar a quienes supuestamente habían tomado "el mal camino", reforzaban prácticas punitivas y de socialización que conducían a perpetuar, por un lado, el sufrimiento y estigmatización de los internos, y por otro, su participación en conductas indisciplinadas y delictivas, tanto dentro como fuera de la Escuela. (p. 174)

En otras palabras, no solo los niños con escaso rigor de crianza son los que pueden desviarse de las normas de la familia y llegar a delinquir, sino también aquellos que tuvieron un exceso de normas (el caso de Canilla, joven de clase 
media a cargo del cuidado de su tía es clara muestra de ello) y que buscaron en los amigos y la calle la oportunidad para expulsar sus impulsos reprimidos.

\section{Conclusiones}

En Los hijos del orden se denuncia el fracaso del sistema penitenciario de las ciudades en proceso de modernización; el hecho de purgar condena encerrados en una prisión-reformatorio como "Maranguita" no libera a los reclusos de los suplicios y castigos físicos de las fuerzas represivas del Estado. En este sentido, sus cárceles están lejos de reformar las conductas delictivas de los prisioneros, pues, antes que buscar la reformación del interno y posibilitar su reinserción productiva en la sociedad, las penitenciarías en los países premodernos se han instituido para controlar y castigar severamente a los que incurren en delito.

Por otro lado, la novela Los bijos del orden presenta un sistema penitenciario basado en sesgos raciales y prejuicios socioeconómicos donde prima el sufrimiento, la venganza y la corrupción de sus autoridades. Los tormentos que padecen los internos de la novela, todos menores de edad y de procedencia humilde, nos llevan a pensar que los castigos que ocurren en las prisiones están dirigidos a grupos subalternos "incivilizados", "bárbaros" y pobres.

\section{Notas}

1 Todas las citas de Los hijos del orden que presentamos en este estudio, pertenecen a la segunda edición de la novela, publicada por el Grupo Editorial Arteidea (Lima, 1994). Después de cada cita, vamos a señalar solo el número de página.

2 No olvidemos que la categoría de la subalternidad incluye a las mujeres entre uno de los grupos históricamente oprimidos. Ahora, ante la pregunta "¿puede hablar el sujeto subalterno?”, Spivak se detiene en lo problemático que resulta en este contexto la cuestión de la mujer: "En una palabra: si se es pobre, negra y mujer la subalternidad aparece por triplicado" (1998, p. 208). En el texto, cambiaríamos lo de mujer negra por la de mestiza con marcadas facciones andinas.

3 El concepto de "violencia simbólica" fue instituido por el sociólogo francés Pierre Bourdieu, en la década del setenta del siglo pasado. Según Bourdieu, "La violencia simbólica, una aparente contradictio in terminis, es, al contrario de la violencia física, una violencia que se ejerce sin coacción física a través de las diferentes formas simbólicas que configuran las mentes y dan sentido a la acción. La raíz de la violencia simbólica se halla en el hecho de que los dominados se piensen a sí mismos con las categorías de los dominantes. La violencia simbólica se ejerce mediante las mismas formas simbólicas adoptadas por los dominados para interpretar el mundo, lo que implica simultáneamente conocimiento y desconocimiento de su carácter de violencia o imposición". (2005, pp. 14-15). Por otro lado, para Richard Leonardo (2016) la violencia simbólica se evidencia en el hecho de que algunos individuos de la cultura subalternizada asumen como propio el discurso del grupo de poder y reproducen sus estrategias de hegemonía. (p. 102). 
4 Es necesario tener en cuenta que aparte de su simbología como representante del mundo delictivo y del orden represivo, en esta pelea se enfrentan, también, un adolescente y un adulto. Esto nos permite llegar a la conclusión que, respecto del mundo de los adultos, ser adolescente es otra de las formas de experimentar la subalternidad.

5 La violencia ejercida por la autoridad se puede justificar en ese estado fronterizo en el que se encuentra el adolescente. Debido a su estado liminal, se pueden rastrear en él determinados rasgos y comportamientos de un adulto, de tal manera que estos proyecten la visión de su propio futuro.

6 La matanza perpetrada por fuerzas especiales del ejército peruano en la cárcel de El Frontón, ocurrida durante el gobierno de Alan García en el año 1986, es clara muestra de ello.

7 Para conocer con profundidad los importantes aportes de Carlos Aguirre sobre la historia de las prisiones en el Perú, se recomienda consultar su estudio Dénle duro que no siente: poder y transgresión en el Perú republicano (2011).

8 La penitenciaría respondía a necesidades y objetivos muy concretos. Se trataba de un diseño punitivo que buscaba eficacia en la represión del delito, encerrando a los delincuentes para convertirlos en seres útiles, obedientes, laboriosos, disciplinados. (Aguirre, 2011, p. 107).

9 En Los hijos del orden, la mayoría de edad se alcanza a los 18 años.

10 Los hijos del orden, a pesar de ser un texto ficcional, refiere sus acciones dentro de un mundo representado de factible lectura y reconocimiento. Esta representación puede constatarse con elementos de la realidad muy familiares para el autor de la novela y para los que hemos caminado alguna vez por las calles de Lima o sus alrededores; por ejemplo, se mencionan nombres de distritos de la capital (San Miguel, Bellavista, Surquillo, El Agustino, La Victoria, Comas, etc.), ubicaciones emblemáticas de Lima (La Parada), calles y avenidas de la capital (av. Abancay, Jr. Puno, etc.), medios de comunicación (Panamericana Televisión), prisiones (El Sexto, El Frontón, etc.) y el único centro reformatorio para menores de Lima, ubicado en San Miguel, y tristemente conocido como "Maranguita".

11 Información extraída de la web del Poder Judicial. Para mayor información, consulte: http://historico.pj.gob.pe/CorteSuprema/GerenciaGeneral/gcj/lima.shtml

12 A las clásicas prohibiciones de visitas, hay que sumarle el aislamiento en calabozos, el rapado de cabello, los baños de madrugada, las violaciones permitidas y el hambre que sistemáticamente se le hacían pasar a los internos que se mostraban remisos a las órdenes.

13 Pero la ley — tanto en su formulación como en su aplicación - no está por encima de los intereses y conflictos que informan las acciones de los seres humanos. Responde a determinadas maneras de ver el mundo (incluyendo concepciones filosóficas, mentalidades y valores culturales), a ciertos intereses particulares (de clase, de género, de grupo) y a formas específicas de concebir el estado y su relación con la sociedad civil y los ciudadanos (formas de control y coerción, prácticas punitivas). Con frecuencia refleja también prejuicios arraigados (religiosos, étnicos, culturales) y sirve para perpetuar (o en ocasiones, desmantelar) mecanismos de exclusión y marginalización. (Aguirre, 2011, p. 16)

\section{Referencias}

Aguirre, Carlos. (2011). Dénle duro que no siente: poder y transgresión en el Perú republicano. Lima: Asociación Fondo de Investigadores y Editores

Foucault, Michel. (1992). Vigilar y castigar. Madrid: Siglo XXI de España Editores. 
Leonardo, Richard. (2016). El cuerpo mirado. La narrativa afroperuana en el siglo XX. Lima: Fondo Editorial, Universidad San Ignacio de Loyola.

Spivak, Gayatri. (2003). ¿Puede hablar el sujeto subalterno? Revista Colombiana de Antropologia 39, 297-364. Recuperado de http://saberesdescoloniales.universidaddescolonial.org/wp-content/uploads/downloads/2012/08/spivak_puede_hablar_lo_subalterno.pdf

Urteaga, Luis. (1994). Los hijos del orden. Lima: Arteidea Editores. 